\title{
Zinc and Copper Recovery from Smelter Waste Stream Case Study
}

\author{
Frank Su* and Songlin Ye \\ BQE Water, Vancouver, Canada
}

\begin{abstract}
Recycling valuable metals from waste streams has become increasingly important to the mining and smelting industry in China due to resource depletion and environmental concerns. Predicated on multiple large scale metal recovery operations designed by BQE Water at active mines in the Jiangxi Province of China, this paper presents a case study demonstrating recovery of zinc and copper from the waste stream at a major gold smelter in the Shandong Province of China. One of the issues facing the smelter is the lack of a cost-effective and robust process to recover zinc from the acidic process waste stream. As such, significant amounts of zinc-containing wastewater are neutralized with lime, resulting in not only the loss of zinc metal but also the generation of large volumes of sludge. In the case study, a sulphide precipitation process is chosen to selectively recover zinc and copper from the wastewater, in the form of commercial grade metal concentrates that can be sold as regular concentrates at the going market price. In the current project phase, over 2,500 tonnes of zinc metal and 40 tonnes of copper metal can be recovered on an annual basis. This not only generates revenue to offset waste treatment costs, but also eliminates significant amounts of sludge that would otherwise require storing and further disposal if the metals are not recovered.
\end{abstract}

Keywords: metal recovery, smelter waste stream, smelter wastewater, sludge elimination, recycling economy

\section{Introduction / Background}

With resource depletion becoming a global concern and environmental regulations becoming increasingly strict, companies in the mining and smelting industry are actively seeking technologies to maximize resource recovery and provide concurrent minimization of waste residue production from operational activities. Mining and smelting companies have typically used lime neutralization as the primary method to reduce metal concentrations from mine waters prior to reuse or discharge to the environment. However, this process creates large volumes of metal laden sludge with long-term liabilities in the form of ongoing storage and management (Zinck et al 1997). Recovering metals of value from mine water not only reduces sludge volumes and the costs of associated liabilities, it produces a commercial grade metal concentrate that can be sold to generate revenues to offset treatment costs.

ChemSulphide ${ }^{\circledR}$ is a sulphide precipitation process developed by BQE Water that has been successfully applied at mine sites in the Jiangxi Province of China to remove and recover copper from acid mine drainage. The success of these copper recovery water treatment plants demonstrates both the economic and environmental benefits of recovering residual metals from mine water and provides reference for the copper and zinc recovery project at a gold smelter in the Shandong Province that is the subject of this case study.

\section{Jiangxi Water Treatment Plants}

The first copper recovery plant utilizing ChemSulphide ${ }^{\circledR}$ was built and commissioned in 2008 to treat acid mine drainage generated from waste rock dumps at Jiangxi Copper Corporation's (JCC) Dexing Copper Mine (Consigny and Kratochvil 2011). With an annual copper production of 130,000 tonnes, the mine is the largest open pit copper mine in China.

Collected mine drainage is first pre-treated with lime to remove ferric iron followed by a copper removal/recovery circuit. From there, the effluent is further neutralized with lime prior to discharge or re-used at the mine site. Copper is recovered in the form of a commercial grade copper concentrate. The sales revenue generated fully covers the pretreatment and copper recovery costs and the surplus can largely offset the downstream neutralization cost.

In 2014, a second ChemSulphide ${ }^{\circledR}$ copper recovery plant was built and commissioned to provide additional treatment capacity at the mine site. In the same year, a ChemSulphide ${ }^{\circledR}$ plant was also built and commissioned at JCC's nearby Yinshan Copper and Zinc Mine (Kratochvil et al 2015). The plant currently recovers copper and is in the process of adding a zinc recovery circuit.

All three plants have been operating smoothly since their commissioning and have delivered positive economic and environmental benefits.

Table 1 summarizes the amount of lime saved and the volume of sludge that is not produced per year when copper is recovered from the mine water at the two mine sites.

\footnotetext{
* Corresponding Author: F. Su, fsu@bqewater.com, phone: +8615967187921

Copyright $\odot 2017$ Canamaple Academia Services, http://press.camdemia.ca

DOI: 10.15273 /gree.2017.02.012
} 
Table 1. JCC ChemSulphide ${ }^{\circledR}$ Plants - Lime \& Sludge Reduction.

\begin{tabular}{lccc}
\hline Plant & $\begin{array}{c}\text { Plant Capacity } \\
\left(\mathbf{m}^{\mathbf{3}} / \mathbf{h r}\right)\end{array}$ & $\begin{array}{c}\text { Lime Saved } \\
\text { (tonnes/yr) }\end{array}$ & $\begin{array}{c}\text { Sludge Reduction } \\
(\mathbf{m} \mathbf{3} / \mathbf{y r})\end{array}$ \\
\hline Dexing 1 \& 2 & 1,000 & $\sim 2,000$ & $\sim 10,000$ \\
& 1,000 & & \\
\hline Yinshan & 700 & $\sim 600$ & $\sim 3,000$ \\
\hline
\end{tabular}

Table 2 outlines the amount of copper that is recovered annually from the acid mine drainage at both Dexing and Yinshan Mines. This copper concentrate is sold to a smelter and generates incremental revenues for the operations.

The results achieved with the ChemSulphide ${ }^{\circledR}$ plants by JCC at these sites demonstrates the significant economic and environmental benefits of implementing metal recovery for the mining and smelting industry.

Table 2. JCC ChemSulphide ${ }^{\circledR}$ Plants - Copper Recovery.

\begin{tabular}{lrrrrrr}
\hline Plant & \multicolumn{6}{c}{ Copper Recovery (tonnes/yr) } \\
& $\mathbf{2 0 1 1}$ & $\mathbf{2 0 1 2}$ & $\mathbf{2 0 1 3}$ & $\mathbf{2 0 1 4}$ & $\mathbf{2 0 1 5}$ & $\mathbf{2 0 1 6}$ \\
\hline Dexing 1 \& 2 & 780 & 893 & 824 & 1,050 & 1,140 & 1,637 \\
\hline Yinshan & & & & 89 & 270 & 382 \\
\hline
\end{tabular}

\section{Case Study: Gold Smelter}

A gold smelter in the Shandong Province of China produces an acidic wastewater stream with a similar chemical nature to the acid mine drainage at the Dexing and Yinshan Mines in Jiangxi Province. The acidic stream contains valuable dissolved metals including copper, zinc, nickel and cobalt. Currently the stream is being neutralized with lime and the treated water is recycled for process re-use at the smelter. All metals report to a voluminous hydroxide sludge that is stored onsite for further disposal.

As one of the largest gold smelters/refineries in China, the facility produces over 20 tonnes of gold and over 30,000 tonnes of cathode copper each year. During the process, the gold concentrate that contains considerable amounts of copper and zinc is leached with cyanide. The solution is then separated for gold cyanidation while the residual is further leached with sulphuric acid to make feed for processing using solvent extraction/electro-winning (SX-EW) technology to produce cathode copper.

The acidic raffinate exiting the SX-EW circuit contains high concentrations of zinc, but is neutralized with lime due to the lack of a reliable and cost-effective solution to recover the zinc. Over the years, the smelter conducted multiple tests and pilots for zinc recovery including using SX-EW, but none proved feasible. A flowsheet of the overall current process at the gold smelter is provided in Figure 1.

Based on historical data collected at the site, the average flow rate of the raffinate solution is approximately $2,000 \mathrm{~m}^{3} / \mathrm{d}$. The solution contains concentrations ranging between $5 \mathrm{~g} / \mathrm{L}$ and $7 \mathrm{~g} / \mathrm{L}$ zinc and between $0.06 \mathrm{~g} / \mathrm{L}$ and $0.12 \mathrm{~g} / \mathrm{L}$ copper. Figure 2 shows the copper and zinc concentration data collected between 2011 and 2016. The results are averaged for the year using grab samples.

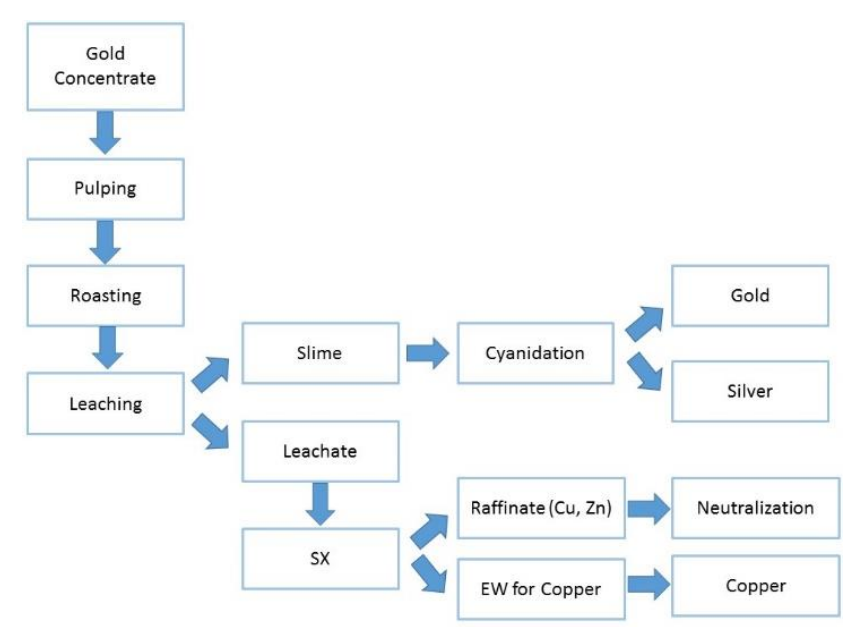

Figure 1. Current Smelter Process Flowsheet.

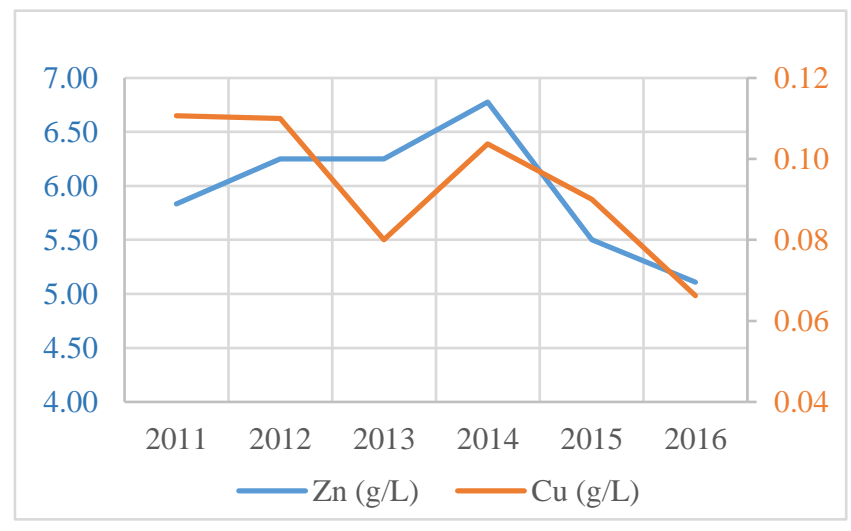

Figure 2. Smelter Raffinate Copper \& Zinc Concentrations.

\subsection{Project objectives}

With the current operation, the copper and zinc metals in the raffinate are neutralized and deport to the waste sludge. This practice fails to recover the valuable metals and in doing so, generates large volumes of hydroxide sludge requiring further handling and disposal. These liabilities result in additional long-term operating costs, possibly in perpetuity.

In comparison, recovering the copper and zinc from the raffinate stream will have significant economic and environmental benefits. These benefits have contributed to defining the objectives for metal recovery and include the following:

- Reduce sludge generation and direct sludge handling, disposal and management costs;

- Eliminate or reduce the deportment of metals as sludge to reduce environmental liabilities;

- Eliminate or reduce the consumption of lime required for neutralization; and

- Create a revenue stream for the operation - make metal recovery not only pay for itself, but also have a surplus to offset further water treatment costs. 


\subsection{The ChemSulphide ${ }^{\circledR}$ plant design parameters}

Given the raffinate average flow rate of $2,000 \mathrm{~m}^{3} / \mathrm{d}$ and the historical copper and zinc concentrations data collected, a ChemSulphide ${ }^{\circledR}$ plant with a hydraulic capacity of $85 \mathrm{~m}^{3} / \mathrm{hr}$ has been designed for the gold smelter based on the key design and performance parameters presented in Table 3.

Table 3. ChemSulphide ${ }^{\circledR}$ Plant Design Parameters.

\begin{tabular}{lccc}
\hline Metal & $\begin{array}{c}\text { Metal } \\
\text { Recovery } \\
(\boldsymbol{\%})\end{array}$ & $\begin{array}{c}\text { Feed } \\
\text { Concentration } \\
(\mathbf{g} / \mathbf{L})\end{array}$ & $\begin{array}{c}\text { Sulphide Metal } \\
\text { Grade } \\
(\boldsymbol{\%})\end{array}$ \\
\hline Copper & $>95$ & $>0.06$ & $>35$ \\
\hline Zinc & $>85$ & $>5$ & $>50$ \\
\hline
\end{tabular}

\subsection{The ChemSulphide ${ }^{\circledR}$ plant process}

The ChemSulphide ${ }^{\circledR}$ process uses a chemical source of sulphide to selectively precipitate and recover dissolved copper and zinc (Bratty et al 2009). The sulphide reagent is added to the waste stream under controlled conditions to form insoluble metal sulphide solids that can be easily dewatered. The high-grade copper and zinc sulphides can be sold as regular metal concentrates and usually at favorable commercial terms due to its high purity. The effluent after the metals recovery is recycled to the smelter's terminal water treatment facility for further treatment prior to reuse.

The ChemSulphide ${ }^{\circledR}$ plant designed by BQE Water for the smelter has three stages: ferric/arsenic removal, copper recovery and zinc recovery. Figure 3 below shows the overall process in a simplified block diagram.

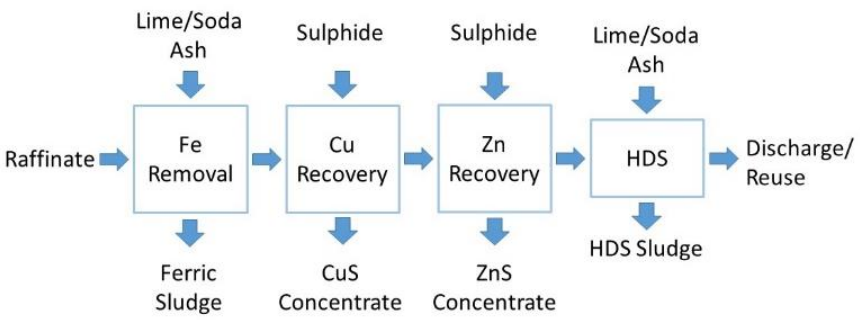

Figure 3. ChemSulphide ${ }^{\circledR}$ Plant Process.

In the first ferric/arsenic removal stage, ferrous is oxidized to ferric and trivalent arsenic is converted to pentavalent arsenic by sparging air into the reactor as per equation 1 . Ferrous has a higher solubility factor than ferric and therefore is more difficult to precipitate from water.

$$
4 \mathrm{Fe}^{2+}+\mathrm{O}_{2}+4 \mathrm{H}^{+} \rightarrow 4 \mathrm{Fe}^{3+}+2 \mathrm{H}_{2} \mathrm{O}
$$

Meanwhile, lime is added to the ferric contactor to precipitate ferric iron and arsenic as ferric hydroxide and iron arsenate as per reaction 2 .

$2 \mathrm{Fe}^{3+}+3 \mathrm{SO}_{4}{ }^{2-}+3 \mathrm{Ca}(\mathrm{OH})_{2}+6 \mathrm{H}_{2} \mathrm{O} \rightarrow 2 \mathrm{Fe}(\mathrm{OH})_{3}+$ $3 \mathrm{CaSO}_{4} \cdot 2 \mathrm{H}_{2} \mathrm{O}$
Removing ferric before copper and zinc recovery increases the copper and zinc concentrate grade and reduces chemical sulphide $\left(\mathrm{S}^{2-}\right)$ consumption associated with ferric to ferrous iron reduction.

In the second stage, sulphide is added to the copper contactor where it reacts with the copper ions per reaction 3 .

$$
\mathrm{Cu}^{2+}{ }_{(\mathrm{aq})}+\mathrm{S}^{2-}{ }_{(\mathrm{aq})} \rightarrow \mathrm{CuS}_{(\mathrm{s})}
$$

The resultant copper sulphide slurry is clarified to produce treated water that is then sent to the zinc recovery circuit to recover zinc. The copper sulphide solids can be dewatered in a filter press and sold as copper concentrate.

A similar process is applied at the zinc recovery circuit. Sulphide is added to the zinc contactor where it reacts with the zinc metals as per reaction 4 .

$$
\mathrm{Zn}^{2+}{ }_{(\mathrm{aq})}+\mathrm{S}^{2-}{ }_{(\mathrm{aq})} \rightarrow \mathrm{ZnS}_{(\mathrm{s})}
$$

After clarification, the zinc sulphide slurry is sent to the fully automated filter press for dewatering and the resultant filter cakes can be sold to a zinc smelter to generate revenues to offset operational and water treatment costs. The effluent of the zinc recovery circuit is pumped to the smelter's terminal water treatment plant for further treatment.

\subsection{Projected plant results: metal recovery, sludge \& lime use reduction}

Based on the gold smelter raffinate chemistry and flowrate, the ChemSulphide ${ }^{\circledR}$ plant is projected to recover over 40 tonnes of copper and over 2,500 tonnes of zinc annually. Presently, both metals are deporting to the waste sludge after lime neutralization and the value of these metals are not being realized. Rather, they are currently contributing to the large volumes of sludge that is being produced.

In recovering the above amounts of copper and zinc, the smelter expects to eliminate the generation of approximately 4,000 tonnes of sludge on a dry weight basis each year. The sludge reduction in terms of tonnage and volume becomes more significant given that the sludge is handled on wet basis in practice.

Additionally, the smelter will save approximately 2,500 tonnes of lime every year that is currently being used to precipitate the metals from the raffinate.

\subsection{Projected plant environmental and economic benefits}

Recovering both copper and zinc from the gold smelter raffinate will have a direct positive impact of permanently eliminating over 2,540 tonnes of metals each year from the environment. These metals are currently contained in the hydroxide waste sludge and have the potential to remobilize into the environment.

Economic benefits of the project are also achieved with the revenues generated from the sale of the metals recovered. Based on BQE Water's ChemSulphide ${ }^{\circledR}$ plant operation experience and factoring in the smelter's local pricing, the revenues generated from the metal concentrate sales will provide a pay back on the plant capital in less than eight years. 
This calculation is based on the assumption of conservative commodity prices going forward. The pay back will be shorter should the commodity market bounce back.

The economic benefits become even more significant if the value of the reduction in lime consumption and the liabilities associated with reduced sludge are also included.

\subsection{Project Status}

The project to implement a ChemSulphide ${ }^{\circledR}$ plant at the gold smelter has obtained all the required permits, including the Environmental Impact Assessment (EIA) approval. Construction of the plant will start in Spring 2017 with plant installation and commissioning expected to be completed in late 2017. The plant is scheduled to be in full operation by January 2018.

\section{Conclusions}

Recovering value from waste in any industry is becoming a highly topical issue. The mining and metallurgical industry produces waste streams that often contain valuable metals that can be recovered and in the process, improve project economics and the environmental profile of the project.

Historically, acidic wastewater has been neutralized with lime to precipitate metals as metal hydroxides that becomes waste sludge. Lime is widely used due to its low cost and availability, but its limitations are leading site owners to seek other options. The large volume of hydroxide waste sludge generated by lime can readily re-dissolve and requires proper handling, impoundment and disposal, as well as long-term monitoring to ensure it does not remobilize into the environment. Significant costs are associated with the management of waste sludge.

In contrast, the utilization of the ChemSulphide ${ }^{\circledR}$ process to recover metals not only generates revenues to offset water treatment cost, but also eliminates or reduces the generation of metal containing waste sludge.

By applying the ChemSulphide ${ }^{\circledR}$ process to recover copper and zinc from their raffinate waste stream, the gold smelter is expected to recover over 40 tonnes of copper and over 2,500 tonnes of zinc on an annual basis. In addition, the smelter will save approximately 2,500 tonnes of lime and eliminate the generation of 4,000 tonnes of sludge on a dry weight basis every year. This solution enables the gold smelter to improve project economics and reduce their environmental liabilities.

\section{References}

Bratty, M., D. Sanguinetti and D. Kratochvil, 2009. Lower life cycle costs for water treatment. In Proc. of the 11th Intl Symposium on Environmental Issues and Waste Management in Energy and Mineral Production, Banff, Canada, 95 - 101.

Consigny, A. and D. Kratochvil, 2011. Sulphide precipitation and ion exchange technologies for cost effective removal of selected metals in wastewater. In Proc. of the 50th Annual Conference of Metallurgists, Montreal, Canada, VI: 413 - 421.

Kratochvil, D., S. Ye and O. Lopez, 2015. Commercial case studies of Life Cycle Cost reduction of ARD treatment with sulphide precipitation. In Proc. of the 10th International Conference on Acid Rock Drainage, Santiago, Chile, 933 - 942.

Zinck, J.M., L.J. Wilson, T.T. Chen, W. Griffith, S. Mikhal and A. M. Turcotte, 1997. Characterization and stability of acid mine drainage treatment sludges. MEND Project 3.42.2a. 